\title{
Documentos, mapas y arqueología: decifrando dos grupos étnicos entre 1400 y 1600 en la Amazónia norte de Equador, algunas inferencias
}

\author{
Documents, Maps and Archaeology: Decoding two ethnic \\ groups between 1400 and 1600 in Northern Amazon of Ecuador
}

Adolfo Jorge Arellano ${ }^{1}$

DOI: https://doi.org/10.26512/rbla.v10i2.20939

Recebido em abril de 2018

Aceito em maio de 2018

\section{Resumen}

El presente trabajo tiene como finalidad considerar que a pesar de la irrupción Española, el proceso de desarrollo histórico cultural tuvo continuídad en las sociedades amazónicas de las regiones interfluviales del Norte del Ecuador. Para inferir este proceso se analizan documentos y mapas producidos durante los primeros siglos de la colonia, y nuevas evidencias arqueológicas asociadas con fechas radiocarbónicas cercanas a la presencia hispana. A partir de este análisis se confirma que dos importantes grupos étnicos ocuparon entre 1400 y 1600 d. C. el Norte amazónico. Los Omagua-Yete a lo largo del curso del río Coca y los Encabellados divididos en dos subgrupos entre el Napo y Putumayo. Así mismo se infiere que los Omagua no fueron portadores de la tradición de cerámica polícroma (Fase Napo), si no más bien estuvieron asociados a la tradición de cerámica corrugada con el nuevo estilo decorativo de falsocorrugado. Por otra parte, la distribución geográfica de las evidencias arqueológicas sugiere que los Encabellados conformaron varias tribus, las que posteriormente fueron denominados con nombres específicos.

Palabras clave: Ecuador, Norte amazónico. Documentos, mapas y arqueología. Período 1400-1600 d.C. Omagua-Yete. Encabellados.

\begin{abstract}
The purpose of this paper is to examine whether, despite the arrival of the Spaniards among Amazon societies residing in the interfluvial regions of Norther Ecuador, the process of historical and cultural development demonstrated continuity. To achieve this, documents and maps produced during the first centuries of the colonial period were analyzed, along with new archaeological evidence from carbon 14 dating. This study confirmed that two major ethnic groups occupied the Northern Ecuadorian Amazon between 1400 and 1600 AD. The Omagua-Yete resided along the Coca River, and the Encabellados were divided in two subgroups between the Napo and Putumayo Rivers. It is suggested that the OmaguaYete did not use the polychrome pottery tradition (Napo Phase) but developed the new

${ }^{1}$ Associate Researcher, Department of Anthropology, Smithsonian Institution. E-mail: ArellanoA@si.edu.
\end{abstract}


decorative style of false corrugation based on their prior use of the corrugated pottery tradition. On the other hand, the geographic distribution of the archaeological evidence indicated that the Encabellados were divided into several tribes under different names, which were given them during the colonial period.

Keywords: Ecuador, Northern Amazon. Documents, maps and archaeology. 1400 - 1600 AC period. Omagua-Yete. Encabellados.

\section{Introduccion}

Desde la primera entrada española de Gonzalo Díaz de Pineda en 1538 a las sierras subandinas de los Quijos y de la expedición de Gonzalo Pizarro y Francisco de Orellana en 1541-42 al subandino y tierras amazónicas, transcurrieron 149 años hasta la presencia de los Jesuitas para la elaboración de un mapa conforme a la información geográfica conocida por los colonizadores. En este siglo y medio las etnias indígenas del subandino se transformaron socialmente pero mantenían los tradicionales contactos con las etnias amazónicas que habitaban el cinturón marginal amazónico. Estas últimas por su parte, fueron poco conocidas y superficialmente registradas y continuaron con sus sistemas económicosociales hasta muy avanzada la colonia. En el norte amazónico de Ecuador, dos grupos étnicos fueron conocidos desde inicios de la colonia, los Omagua del Napo y los Encabellados de las regiones interfluviales.

En este sentido, el apreciable número de evidencias arqueológicas registradas en las regiones interfluviales proporcionan una apertura a la posibilidad de correlacionar los dos últimos períodos de ocupación de la tradición de cerámica corrugada- falsocorrugada (Ochoa 2007), con estos dos grupos étnicos descritos en los primeros documentos asociados a la ocupación española de las sierras subandinas y posteriormente la Amazonía marginal. Para inferir esta relación se incluyen al analísis documental, mapas y la secuencia arqueológica establecida para el norte amazónico. No obstante, se debe tomar en cuenta que exísten limitaciones para una integración entre idéntidades étnicas y lingüísticas y cultura material arqueológica.

La mayor parte de los asentamientos arqueológicos del Norte amazónico están cronológicamente ubicados en el período de Integración (500 a 1500 d.C.). En este período, dos tradiciones cerámicas fueron parte del desarrollo socio-cultural de la región, primero la tradición polícroma y luego la tradición corrugada. Esta última adquiere relevancia durante la difusión del estilo de decoración falsocorrugada. Para efectos del presente artículo se considera solo las evidencias que están relacionadas con dataciones $\mathrm{C}^{14}$ cercanas a 1450 d.C. y las cuales, según sus desviaciones estandar pueden apróximarse a la época de la conquista y descubrimiento del Río Amazonas.

Los actuales grupos étnicos amazónicos que tienen sus asentamientos y territorios en las regiones interfluviales del Norte amazónico de Ecuador son: Cofán, Siona, Secoya y Shuar. Sus principales asentamientos se ubican con 
preferencia en la orilla de los ríos de mayor caudal. Los Cofán se encuentran en la orilla izquierda del Aguarico, en el área de la confluencia del Río Dureno y en la orilla derecha frente a la confluencia del Río Zabalo. Los Secoya en la orilla izquierda del Aguarico cerca de la frontera con Perú y en la confluencia del Río Shushufindi. Según Vickers (2003:47), los Secoya indican que sus ancestros provienen del Perú y que tienen relación con el río denominado "Si'e koya", tributario del Río Santa María. Por su parte los Shuar se encuentran asentados en la orilla derecha del Aguarico y los Siona en el Río Cuyabeno, estos últimos podrían ser descendientes de los Encabellados (Vickers 2003:47). Con el avance de la colonización los quichua amazónicos se establecieron a lo largo de la orilla derecha del Napo formando pequeñas unidades familiares y cerca de la laguna Zancudo en la orilla derecha del Aguarico. Actualmente al Sur del Napo no exísten asentamientos estables de grupos étnicos, algunas informaciones señalan la presencia de algunas famílias Waorani en la subcuenca del Yasuni.

En el mapa etnolingüístico de Steward (1950) se puede apreciar de manera general que en el espacio geográfico del presente artículo, dos etnias ocuparon las serranias subandinas; Canelo y Quijo, mientrás en la alta amazonía o piedemonte amazónico fueron reconocidos los Gae, Semigae y Cofán. En la baja amazonía con relación al curso del Río Napo se pueden distinguir los Sioni, Pioje y Encabellado en la orilla izquierda y por la orilla derecha a los Semigae, Záparo y Awishira. Entre otros datos sobre grupos en la Amazonía baja, se menciona a los Tetete en lo que ahora es la provincia Sucumbios (Aguilera 2003:50).

Es interesante mencionar los territorios etnicos del mapa de Ferdon (1950), los quichua amazónicos están ocupando toda la región interfluvial desde la orilla izquierda del Aguarico hasta el Napo con una extensión por las orillas del Cuyabeno hacia el Putumayo. Los Cofán desde el Río Sán Miguel hasta la cabecera del Río Aguarico incluyendo parte de los ríos Coca y Eno. En éste mapa también se observa que desde el Napo hasta el Río Villano-Curaray se encuentra el territorio de los Sabela, subdivididos en Tschiripuno y Tihuakuna (Auca y Waorani). Ferdon (1950:6) citando a Tessman (1930) indica que un grupo de "treinta a cincuenta" Awishira estuvieron viviendo junto a los Tihuakuna entre el Napo y Tiputini.

La diversidad de grupos tribales en la cuenca del Río Napo fue descrita y mencionada por Alfred Simson en los años 1878 y 1883. Estas descripciones son muy importantes para posteriormente considerar los territorios y la variedad de patrones de asentamiento prehispánico. En sus notas sobre los indígenas del Napo y los Záparo, presenta una clara distinción de las tribus que habitaban las sierras subandinas amazónicas y la Amazonía. En base al consumo de sal los diferencia entre "semi-cristianisados e infieles o Ancas". Los primeros tienen como lengua común el quichua. Los segundos que no consumen sal son: Záparos, Piojes, Cotos, Tutapishcus y Anhishiris, estas cinco 
tribus fueron contactadas, y mencionadas por los indígenas del subandino. A través de noticias de comerciantes y los propios Záparos, Simson (1883:21-22) hace referencia a la probable existencia de Intillamas, Meguanas, Copalurcus, Tamburyacus, Payaguas, Cauranos, Pucabarrancas, Lagarto-cochas y Tagshacurarais. No obstante le parece que no son diferentes tribus y que en realidad son designaciones de localidades, y que estarían conectadas con la tribu denominada y mejor conocida, Iquitos. Además, los Cotos y Tutapishcus son parte de una sola tribu. Sobre los Záparos indica que ocupan el Río Curaray y sus tributarios Nushinu, Nuganu y Supinu. En la cuenca del Río Napo los Záparos se ubican en las cercanías de Sinchisicta y el Yasuni (Simson 1878:502).

Esta diversidad de nombres de grupos tribales asociada con el curso del Río Napo es también confirmada por Tyler (1894), indicando que la tribu Záparo tiene su territorio desde el Napo hasta el Curaray, y que está subdivida en numerosas familias; "Ahuishiris, Andoas, Curayaes, Matagenes, Mautas, Meguanes, Nuganus, Nushinus, Rotunus, Shiripunos, Sinchisctus, Supinos, Tiputinis y Yasunis"(Tyler 1894:478). Se puede observar que la mayor parte de estas denominaciones tribales tienen asociación con la orilla derecha de las cabeceras del Napo y con la sub-cuenca del Curaray, donde se encontraba la mayor densidad demográfica de los Záparo. La mayor parte de estos grupos tribales desaparecieron y solo quedan las referencias. Al Norte del Napo, de acuerdo a los misioneros Capuchinos, en 1913 existían pequeños grupos familiares de Teteté y Sansahuari al norte del río Aguarico.

En la década de los años 1950 a 1960 todavía había evidencias de la presencia de dos famílias de la etnia Tetete habitando en el área de la confluencia del Río Sán Miguel con el Putumayo y "200 a 1000" Auca entre el Napo y Curaray (Emerson y Johnson 1961:201). En 1966 misioneros Capuchinos ubicaron a tres Tetete (una mujer y dos hombres) habitando entre los ríos Cuyabeno y San Miguel (Aguilera 2003). En esta década los grupos étnicos del Norte amazónico fueron conocidos bajo cuatro denominaciones: Yumbo, en la orilla izquierda del Napo hasta la confluencia del Coca; Auca, desde la orilla derecha del Napo hasta el Curaray; Cofán, en le region interfluvial entre el Aguarico y Napo; Secoya, al Norte del Aguarico (Emerson y Johnson 1961:201). Como se mencionó líneas arriba, bajo el denominativo de Auca o Anca, se incluyeron a las tribus que ocupan las regiones centro-sur del bajo amazonas de Ecuador.

En la actualidad todavía se publican noticias de grupos tribales aislados en las regiones interfluviales situadas al Sur del Napo. Entre los ríos TiputiniTivacuno y Curaray se identificaron en el año 2010 tres grupos denominados Curaray, Armadillo y Gabaron, nombrados de esta manera por su relación con el área donde se encuentran asentados. Probablemente estos grupos son derivados del grupo Tagaeri-Taromenani que ocasionalmente tenía contactos con los asentamientos Waorani. Los Waorani en 1958 estaban divididos en cinco clanes: Guikitairi en las cabeceras del Río Curaray; Baiwari en el curso 
medio de los ríos Chiripunu y Tigueno; Piyemoiri en el Tiputini y cabeceras del Tivacuno; Wepeiri en el curso medio del Yasuni y Taromeanane entre los ríos Nashiño y Cononaco (Colleoni y Proaño 2010:11). Por otra parte, las periódicas migraciones de grupos tribales de origen Tagaeri desde los ríos Tivacuno y Tiputini hacia el Sur son mencionadas por Colleoni y Proaño (2010:10).

\section{Las fuentes documentales escritas}

Según los documentos que describen la "gobernación de los Quijos" entre 1559 y 1621 y los producidos por misioneros jesuitas, en especial el de Pablo Maroni, el Norte amazónico de Ecuador en los primeros siglos del período colonial estuvo poblado por grupos étnicos pertenecientes a las lenguas cofán, resígero y a la família lingüística záparo (Steward 1950). Al parecer los Cofán fue una etnia compacta que tenía como territorio el subandino y piedemonte al Oeste de la región interfluvial limitada por el Sán Miguel y el Aguarico, y probablemente fueron los últimos vecinos de las etnias Quijo y Coronado que dominaban las sierras subandinas centrales.

Las primeras noticias de la presencia de etnias en el subandino, el piedemonte andino y amazonía marginal del Ecuador provienen de la relación acerca de la expedición de Gonzalo Pizarro al país de la Canela y de la relación de 1542 de Fray Gaspar de Carvajal participante del contingente español de Francisco de Orellana durante el descubrimiento del río Amazonas.

En el trayecto de Pizarro los pueblos "Capua y Guema" en la confluencia del río Angelo con el Aguarico son descritos como "pueblos indios del Coca". Esta particular región entre 1599-1611 estuvo ocupada por aldeas pobres y dispersas (Chaumeil y Fraysee-Chaumeil 1981:78). De la aldea Capua ubicada en la orilla derecha del alto Coca, enterado Pizarro de las "riquezas que existían río abajo", cruzó a la orilla izquierda, "asentándose en un pequeño caserio llamado Guema" (Santos 1992:62). En el mapa del recorrido de Gonzalo Pizarro y Francisco de Orellana presentado por Chaumeil y Fraysee-Chaumeil (1981), se muestra objetivamente la ubicación de los sitios mencionados en el informe de Gonzalo Pizarro y en la relación de Fray Gaspar de Carvajal. Según esta relación, las orillas del Napo entre las confluencias de los ríos Coca y Aguarico estuvieron despobladas hasta el encuentro de Aparia Menor (Carvajal 1995).

En la interpretación efectuada por Chaumeil y Fraysee-Chaumeil (1981) acerca del itinerario de Pizarro y Orellana en el piedemonte oriental de los Andes y la región amazónica, se menciona que los Omagua-Yeté estuvieron asentados en las orillas del curso medio-inferior del Coca. Los mencionados investigadores consideran que "en el momento del contacto en 1541, los Omagua estuvieron en una fase de replegarse en dirección al Coca". Posteriormente estas áreas fueron re-ocupadas "por los Cofanes entre 1599-1600 en tiempos" del padre Rafael Ferrer. Más tarde en los siglos XVII y XVIII los Omagua-Yete ocuparon 
las cabeceras del río Tiputini. Es probable que los Omagua del Coca iniciaran migraciones forzadas hacia las cabeceras del Napo por la "presión de invasores Tupi desde el Amazonas" y las "plantaciones y aldeas destruídas a lo largo del Aguarico" (Chaumeil y Fraysee-Chaumeil 1981:78) fue un resultado de este movimiento migratorio.

De la misma forma, Reeve (1993:109) sugiere que la presencia TupiOmagua y su relación con el norte amazónico de Ecuador, fue resultado de migraciones hacia el alto Napo y Marañon anteriores al 1500 y de esta manera desarrollaron contactos interculturales mediante un comercio por las redes fluviales. Posiblemente los Omagua asentados en el río Coca comerciaron con los Quijos "oro, ropa, comida y esclavos en sus mercados" (Steward y Metraux 1963:654). Los Omagua tenían ornamentos de oro los cuales eran obtenidos de los Quijos (Chaumeil y Fraysee-Chaumeil 1981:90). Sin embargo, hasta el presente en la Amazonía de Ecuador no fueron registradas evidencias arqueológicas de ornamentos de este preciado metal y tampoco exísten referencias en las relaciones de los misioneros (Metraux 1948:694). No obstante, es más probable que coca y canela fueron los principales productos obtenidos de los Quijos (Porras Garces 1974:23), además de la corteza de quina-quina y que este intercambio tuvo que haberse efectuado en dirección a las cabeceras del Napo y por medio del curso del río Payamino. Los Omagua-Yete del Coca comerciaban con los Quijos y estos también llegaron hasta los Omagua del Amazonas intercambiando sal por "oro en polvo", son estos Omaguas que sirvieron de guías a los Jesuitas (Santos 1992:15). Al parecer estos intercambios comerciales se deterioraron poco después de que los Tupi-Omagua "ayudaron a los Quijos en su rebelión de 1579 contra los españoles asentados en Avila" (Reeve 1993:111). Sin embargo, los Tupi-Omagua estuvieron asentados en 1600 aguas arriba de la confluencia del Coca con el Napo. "En 1605 unos de sus caciques vino a Avila para pedir a los Jesuitas que bautize a su gente" (Reeve 1993:113). Es decir, que los Tupi-Omagua conocían el piedemonte donde estuvo asentada la población de Avila (aprox. $700 \mathrm{~m} \mathrm{snm}$ ) y que conocían el quechua, idioma que los Jesuitas utilizaban para comunicarse con los Quijos.

Consiguientemente y como menciona Reeve (1993:109), los Tupi-Omagua continuaban con su tradición de contactos con el subandino desde antes de la entrada de los Jesuitas al curso del bajo Amazonas. Además estos Omagua fueron los que ayudaron "a contactar los pueblos que vivian en el bajo Napo y bajo Pastaza” (Reeve 1993:121).

Por otra parte, las investigaciones etnohistóricas de Renard-Casevitz et al. (1988) determinaron que durante el período comprendido entre 1600 a 1700 también exístieron varias migraciones de grupos étnicos del Sur de Ecuador y Norte del Perú hacia la zona del Napo. Al mismo tiempo exístieron algunos movimientos migratorios desde la confluencia del Putumayo con el Amazonas hacia la confluencia del Aguarico con el Napo. 
Los Omagua del Napo fueron distintos de aquellos del Amazonas que tenían sus aldeas en las islas del curso medio y orillas del río Amazonas (Metraux 1948:693). Los Omagua del Amazonas estuvieron "organizados en dos entidades separadas, la primera liderizada por un jefe denominado Machiparo y la segunda por un jefe llamado Omagua" (Wilson 1999:243). Machiparo posiblemente controlaba un territorio entre las confluencias de los ríos Putumayo y Jápura, mientras el territorio de Omagua se extendía desde Jápura hasta el río Purus.

Según Oberem (1967-1968), existe una continuidad en la información etnohistórica con relación a los Omagua desde la proporcionada por Gonzalo Pizarro en 1542 acerca de la presencia de este grupo étnico en el curso medio del Coca. Posteriormente, Francisco de Orellana al continuar la exploración por el Napo vuelve a encontrar a los Omagua cerca de la confluencia del Aguarico con el Napo (Chaumeil y Fraysee-Chaumeil 1981). Siguiendo la información proporcionada por Oberem(1967-1968), documentos señalan que posteriormente en 1563 Andrés Contero visitó las provincias de Tapaca y Omagua. En el mismo año José Villamoro Maldonado realiza una expedición a la provincia Omagua y en 1577 el oidor Diego de Ortegón informa la existencia de un río mas allá de la provincia de los Quijos con "indios poblados que se llama tapaca e magua y eguata". Esta particular información sugiere que existía una diversidad de tribus étnicas Omagua asociadas a una sola lengua. Los Omagua ocuparon toda la atención de los españoles en el siglo XVI posiblemente por que fueron los más accesibles en las orillas de los ríos Coca, bajo Napo y Amazonas. Los españoles nunca se internaron en las regiones interfluviales y la información de los pueblos asentados en estas regiones es muy escasa.

De manera similar, documentos coloniales indican que el Norte amazónico se encontraba integrado a la gobernación y obispado de Mainas (Porras 1987). Estos documentos proporcionan una idea de los territorios de los grupos asentados en ambas orillas del Río Napo en la actual región que pertenece a Perú y Brasil, mientrás en lo que corresponde a Ecuador hay menos evidencias. El mapa étnico de Porras (1987:58) proporciona un panorama de la ubicación de los territorios que ocuparon los Semigayes, Pinches y Paguas en la región interfluvial entre el Napo y el Yasuni. Al Norte del Napo las evidencias etnohistóricas sugieren que los grupos hacia el 1600 fueron Omaguas en el margen izquierdo del Coca y Encabellados en la región interfluvial entre el Aguarico y Napo (Renard-Casevitz et al. 1988:58). De igual manera, el mapa de "El Marañon o Amazonas" elaborado por Samuel Fritz entre 1691 y 1707 proporciona una idea de los territorios de las etnias asentadas en la Amazonía ecuatoriana. Entre el Putumayo y Napo están los Encabellados, Sucubios, Yacanaras, Chius y Payahuaras, y al Sur del Napo los Semigayes, Gayes y Abijiras. Por otra parte, Reeve (1994:109) menciona que entre 1538 y 1540 los Omagua "ocuparon las islas del alto Amazonas y vastos territorios a lo largo 
del Napo". También citando documentos de 1605 indica que los Omagua son referidos con diferentes nombres; Sumagua, Arianas, Tapaca, Magua y Eguata. Además que "el territorio de los Omagua se extiende desde la confluencia del Río Coca a la confluencia del Napo y Marañon” (Reeve 1994:132).

Luego de la fundación de Baeza en 1559 en el país de los Quijos, la frontera oriental española se fue ampliando hacia el piedemonte amazónico y en 1563 con la fundación de los pueblos de Archidona y Avila prácticamente se habia establecido la presencia hispana en el subandino. Apartir de estos asentamientos españoles se inició la "evangelización" de los indígenas para introducirlos al sistema de encomiendas. En 1621-22 la misión Jesuita de San Juán de Omaguas en el curso del río Curaray tenía un centenar de famílias. Por su parte, los franciscanos iniciaron la evangelización de los Omagua del Amazonas, denominados "Marañones, Cavari-Manicuri", desde la mitad del siglo XVII (Chaumeil y Fraysee-Chaumeil 1981:81-83).

Entre tanto, la frontera oriental española en el subandino del Sur de Colombia fue creada por Francisco Pérez de Quezada al Norte del río San Miguel, con la fundación de las poblaciones de Mocoa en 1557 y Ecija en 1558, para control de las tribus Mokoa, Putumayo y Sucumbios (Rivet 1952:203).

En 1603 el padre Rafael Ferrer fundó la misión San Pedro de los Cofanes conformada por 3000 individúos de 5 tribus, y en 1604 se fundaron las misiones de Santa Marta y Santa Cruz con 3000 individuos (Rivet 1952:203). Es decir, para entonces los Cofán fueron reconocidos como una etnia con idioma propio y un territorio que comprendía la cuenca alta del río Aguarico, desde el piedemonte hasta la confluencia del río Cuyabeno con el Aguarico, y por el Norte la subcuenca del río San Miguel. Nuevamente, "en 1611, el jesuita Rafael Ferrer visita los Cofán de alto Aguarico y funda misiones" (Chaumeil y Fraysee-Chaumeil 1981:78).

La presencia de los grupos étnicos Cosanes, Sucubios (Sucumbios) y Encabellados en la región interfluvial Aguarico-Putumayo fueron registrados por misioneros franciscanos entre 1632 y 1635 (Izaguirre 1922). Los franciscanos en su relación de 1634 mencionan que luego de su fracasado intento de llegar al Amazonas através del río Sán Miguel, "el padre José Antonio Caicedo se quedo con los Sucumbios". Por su parte, el fraile Pedro Pecador continuó a San Pedro de Alcalá de los Cosanes, desde donde y junto con el capitan Juán de Palacios en diciembre de "1635 embarcaronse en el Aguarico y luego se fueron a los Encabellados". En la denominada provincia de los Encabellados fundaron el pueblo "Ciudad de Sán Diego de los Encabellados" (Izaguirre 1922), probablemente en el mes de Enero de 1636.

En cuanto a Los Encabellados, Casanova (1998:35) concluye que es una etnia que tenían un idioma similar y habitaban "la región comprendida entre el alto río Putumayo y el alto río Napo", "solo aceptaban vivir temporalmente en 
los poblados-reducciones" y que el lugar de sus asentamientos se encontraba en el interior de los regiones interfluviales. Por los nombres nativos de las reducciones que los jesuitas utilizaron en el Napo y Putumayo, se infiere la exístencia de varias ramas o tribus de una misma lengua en el interior de las regiones interfluviales. Según Casanova (1998:32), asociados a las orillas de los ríos Napo, Aguarico, Cuyabino y Santa María, se encontraban las reducciones denominadas Ciecoya, Puequeya, Necoya, Guasitaya, Icahuates, Zeocoya, todos de lengua encabellada.

Los Encabellados también son mencionados en dos oportunidades "1654 y 1664", por los jesuitas que recorrieron el río Marañon desde "el pueblo de Jeberos" con dirección al Alto Napo. En 1654 surcaron el Napo, al llegar, probablemente a la boca del Aguarico, "los indios Jeberos" que los acompañaron tienen un encuentro armado con los Encabellados y luego continúan hasta Puerto Napo (San Román 1994:51). En la segunda oportunidad, los jesuitas bajan el Marañon y entran al Napo hasta llegar a la boca del río Curaray. En el recorrido del Curaray contactan los "indios Quilinos" y posteriormente a los “indios Avijiras” (San Román 1994:53).

\section{Las fuentes documentales gráficas}

De acuerdo a Loreiro Dias (2012:2), no sólo los documentos escritos deben ser considerados como fuentes etnohistóricas, sino también los mapas "que pueden ser tratados como texto" y por consiguiente en estos se pueden "analizar la relación entre el objeto material y su significado".

Los primeros mapas de Sudamérica que muestran el curso del río Amazonas provienen del siglo XVI. La referencia geográfica inicial para la elaboración de estos mapas es la ubicación de las principales ciudades españolas situadas en las sierras andinas. Una de las ciudades, Quito, se encuentra particularmente relacionada con el curso del río Amazonas y en este usualmente se encuentra el nombre Omagua.

Latorre (1988) en su estudio sobre el desarrollo de la cartografía ecuatoriana en el siglo XVIII incluye una serie de mapas de América del Sur y del curso del río Amazonas. El análisis de este material permite inferir que los europeos desde 1550 tenían conocimiento de la exístencia de los grupos étnicos Omagua y Paguana. Sin embargo la representación gráfica del curso del río Amazonas, fué al parecer una copia de la Carta de Diego Gutierres de 1550 que muestra un "río serpenteado" hasta su desembocadura en el Atlántico.

La diferencia entre los siguientes mapas reproducidos por Latorre (1988): Carta de América de Juan Van Doet de 1585, Abraham Ortelius de 1587, Theodore de Bry de 1592, mapa de Brasilea et Peruvia de Cornelius de Jode de 1593 y el de Guillermo Sanson de 1670, es la variabilidad en la ubicación geográfica nominal de las provincias Omagua y Paguana en relación al curso 
del Amazonas. Esta característica sugiere la falta de información geográfica, que también es evidente en el mapa de América de Nicolá y Guillermo Sanson de 1679, en el cual el Amazonas se idéntifica con el río Napo y solo se menciona Aparia Omaguas en su orilla izquierda (Latorre, 1988: 141-142). En esta secuencia, en el mapa del continente americano de Williem Blaeu elaborado entre 1630-1662, la representación del río Amazonas no es serpenteada y en el mapa de América del Sur de Nicolás de Fer de 1705 están incluídas las islas de los Omaguas.

Luego de la publicación del mapa de Cristóbal de Acuña en 1680, existió un mayor enfoque en la representación gráfica del curso del Amazonas y sus tributarios, y en la inclusión de los grupos étnicos que habitaban en sus orillas. La importancia de nombrar los tributarios y las tribus en los mapas posteriores a 1680, puede ser interpretado desde el punto de vista político en relación a la delimitación de las posesiones territoriales de las coronas española y portuguesa.

Sin lugar a dudas el primer mapa en el cual se trazaron los cursos de los ríos Napo y Putumayo con la inclusión de aspectos geográficos y la diversidad étnica en el curso del Río Amazonas, fue realizado por el Jesuita Samuel Fritz. Loureiro Dias (2012) menciona tres ediciones del mapa, la primera de 1707 que vendría a ser la original y luego las posteriores de 1712 y 1717.

Por su parte, Latorre (1988) indica que el primer mapa del río MarañonAmazonas fue realizado por Fritz entre 1689-1691 y fue "donado a La Condamine en 1740 y se conserva en la Biblioteca de París". También menciona un mapa de Fritz de 1701 que se conserva en la Biblioteca Nacional de París y que el mapa de 1707 fué grabado por Juán de Narváez en Quito y "dos copias fueron llevadas por La Condamine" a Europa,"una se conserva en la Biblioteca Nacional de París" y la otra "fue enviada al Rey de España y reposa en la Biblioteca Nacional de Madrid". De igual manera, Loreiro Dias (2012:102) menciona un mapa de 1691 en esta biblioteca y lo considera una versión previa al mapa grabado de 1707 por Juán de Narváez en Quito. (Figura 1). 
Figura 1: Mapa del "Grán Río Marañon o Amazonas”, elaborado por Samuel Fritz y grabado en Quito por Juán de Narvaez en 1707

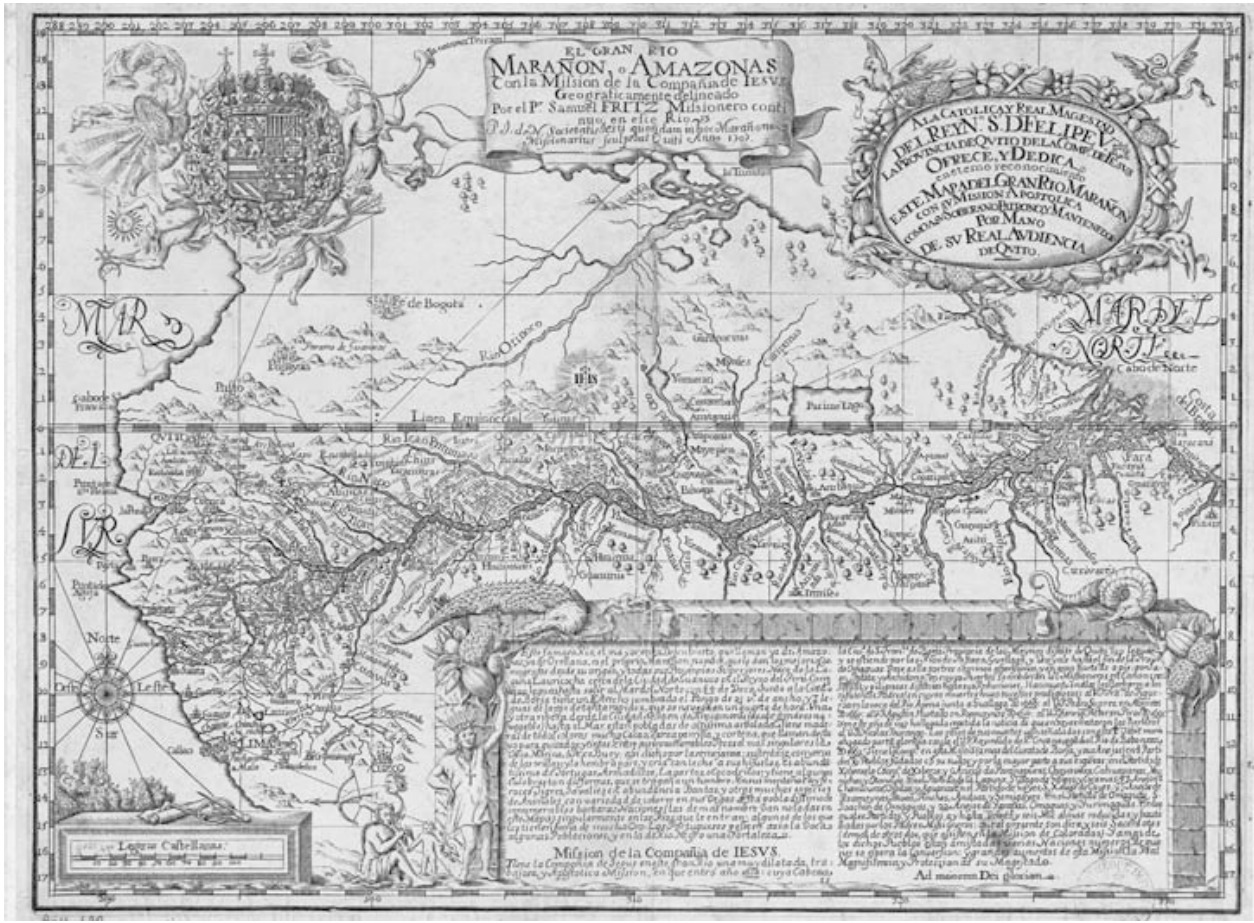

En las diferentes versiones de los mapas de Fritz 1707 a 1717 los grupos étnicos asociados a la cuenca del Napo fueron por el Norte: Encabellados, Sucubios, Yariuaras y Chais. Por el Sur: Semigaes, Abijiras y Yameos (Figura 2). Más tarde según Markham (1865), en 1789 Juán de Velasco en su "Historia del Reino del Quito" menciona los siguientes grupos étnicos asociados al curso del Napo: Abijiras (Abiras, Nevas, Oas, Cunjies) registrados hasta 1667, Simigaes (Acamoris, Arazas, Comacoris, Ginoris, Napotoas, Nepas, Panojoris, Ynuris), Aguaricos (Acaneos, Becabas, Chavelos, Chifias, Neguas Tamas), Encabellados (Ancuteres, Neocayas, Yapuas, Yasheos), Yameos (Ardas, Napeanos), Chais, Cofanes, Comayos, Tiputinis, Yurusunes, Záparos, Zeoqueyas (Zucoyas). Sin embargo, en el mapa de Juán de Velasco anexo a su publicación se observa que sólo se nombran las misiones y excepcionalmente los etnias de la subcuenca del Putumayo (Figura 2). 
Figura 2: Mapa de la Audiencia de Quito, elaborado por Juán de Velasco en 1789

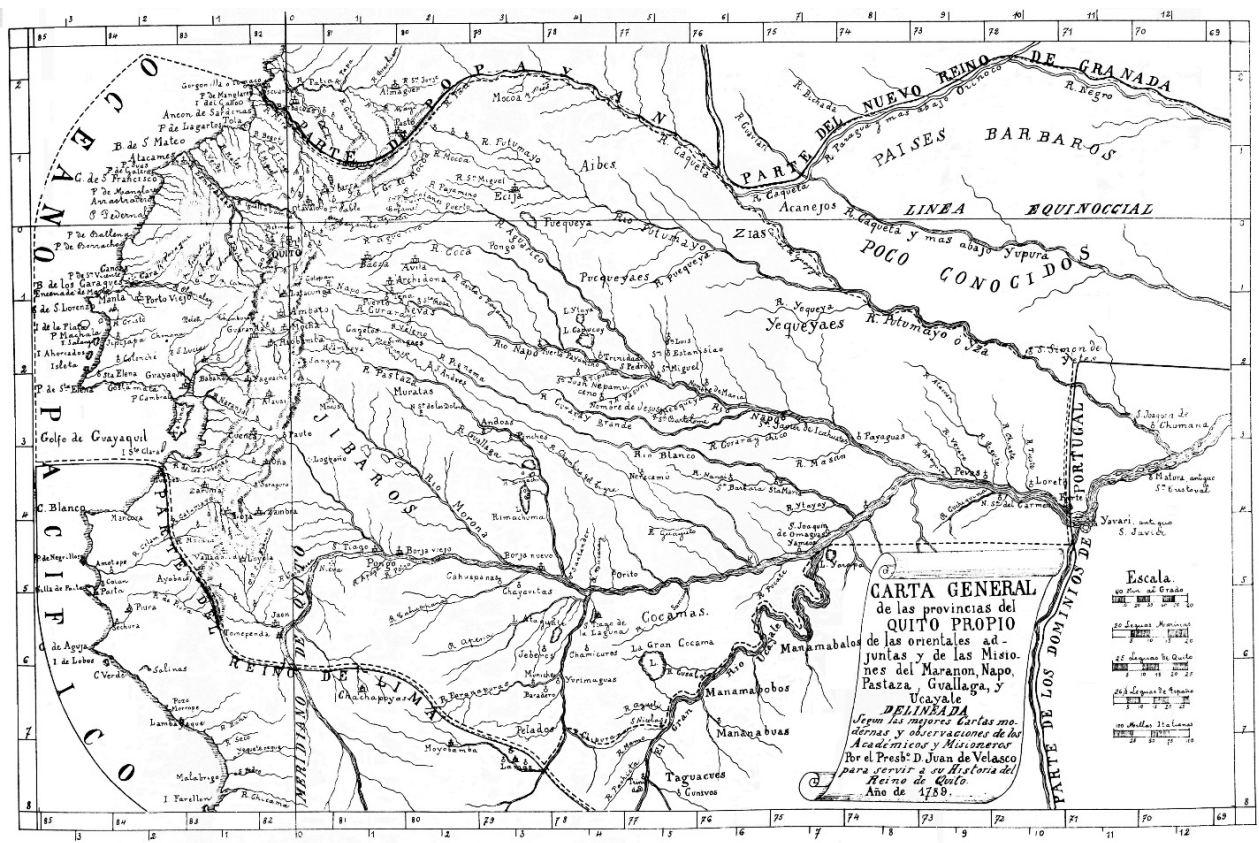

Se debe destacar que el informe de Fritz realizado en 1692, se encuentra enfocado en el trabajo misionero efectuado entre la boca del río Napo y el curso del rio Negro. En el informe se indica que los jesuitas tienen controladas 40 aldeas Omagua, Yurimagua y Aisure (Loureiro Dias 2012:110). Esta referencia es una re-afirmación del control de esta región no solo por los Jesuitas sino también por la corona española. Este informe también implica que Fritz conocía la "lengua franca Kokama/Omagua" que probablemente aprendió durante su estadía entre 1689 a 1691 en Belén (Cabral 1995:304; Yopán 2010:754), y que los Omagua empleaban para su relación con las tribus del Marañon, Huallaga y Ucayali.

En el análisis del contenido socio-político de los mapas de Fritz (17071717) realizado por Loureiro Dias (2012) se menciona que, "la letra " $O$ ", la primera del nombre étnico Omagua, se sitúa precisamente en la boca del río Napo, donde El inició su trabajo misionario, y la última letra "A”, esta localizada cerca de la boca del río Japurá”. En el mapa (grabado) de Fritz de 1707, el topónimo Omagua" se encuentra indiscutiblemente situado en la orilla izquierda del Napo y luego del Amazonas. Este mapa incluye una descripción de los aspectos geográficos relacionados con el curso del río Amazonas; "Fritz también identifica los recursos naturales del río Amazonas que podrían ser suceptibles de explotación económica, y aspectos salvajes e inhóspitos del territorio" y comenta que el territorio está "muy densamente poblado por innumerables naciones bárbaras". Luego menciona el trabajo misionero de los 
Jesuitas desde la provincia de Borja hasta el final del territorio de los Omagua y comenta que con solo 16 misioneros controlaron 39 aldeas de los cuales 23 estuvieron a cargo de Fritz, es decir 26000 almas re-asentadas en aldeas (Loureiro Dias 2012:106-107).

De acuerdo a Loreiro Dias (2012:113), en las posteriores versiones del mapa de Fritz exísten omisiones intencionales. En la publicada en 1717 no se encuentran las representaciones etnográficas y emblemas decorativos, "los símbolos que se refieren a residencias religiosas y pequeñas fortalezas continuan sin ninguna indicación si pertenecen a españoles o portugueses, o jesuitas u otras ordenes". "No hay indicaciones de las misiones indígenas entre los Omagua, que están cuidadosamente delineadas en la versión original”. En los mapas de Fritz, el grupo étnico que se encuentra con bastante énfasis en asociación con el curso del río Amazonas es Omagua. Este nombre desaparece en el mapa de Fritz publicado en Francia en 1717.

De manera similar, exísten omisiones en la versión inglesa publicada en 1712 y posteriormente en la española de 1753 que es una copia de una francesa que tiene correcciones de Charles Marie de La Condamine en relación a información etnográfica e hidrográfica (Loreiro Dias 2012:115).

Es interesante mencionar que los ríos Aguarico y Sán Miguel no se encuentran incluídos en ninguno de los mapas de Fritz. Las representaciones del Aguarico y San Miguel se pueden observar con cierto detalle en el mapa de la Real Audiencia de Quito elaborado en 1779 por Francisco Requena. Luego, diez años más tarde estos dos ríos fueron delíneados en el mapa de Juán de Velasco "dibujado e impreso en 1789 en Madrid" (Latorre 1988:183-184). En el mapa de Acuña de 1680, integrante de la expedición portuguesa de Pedro Texeira, si bien el río Aguarico se encuentra muy bien representado, la ubicación de los ríos Coca y Napo se encuentra distorsionada.

La región interfluvial representada en los mapas de Fritz está limitada por el curso del río Napo y el río Ica o Putumayo. En esta región los grupos étnicos: Encabellados, se encuentra en la orilla izquierda y por la representación de colinas se puede inferir que se ubican muy cercanos al piedemonte andino. Sucubios (en los posteriores mapas Sucumbios), se ubican en la parte media hacia la orilla izquierda del Putumayo. Chius, en la orilla derecha de un tributario del Putumayo (probablemente Puequeya). Yacariuaras, en la parte central y finalmente Payauas en la confluencia del Napo con el Amazonas (Figura 3). 
Figura 3: Extracto del mapa de Fritz de 1707. Ubicación de los grupos étnicos en relación a la representación del curso del Napo en los siglos XVII y XVIII

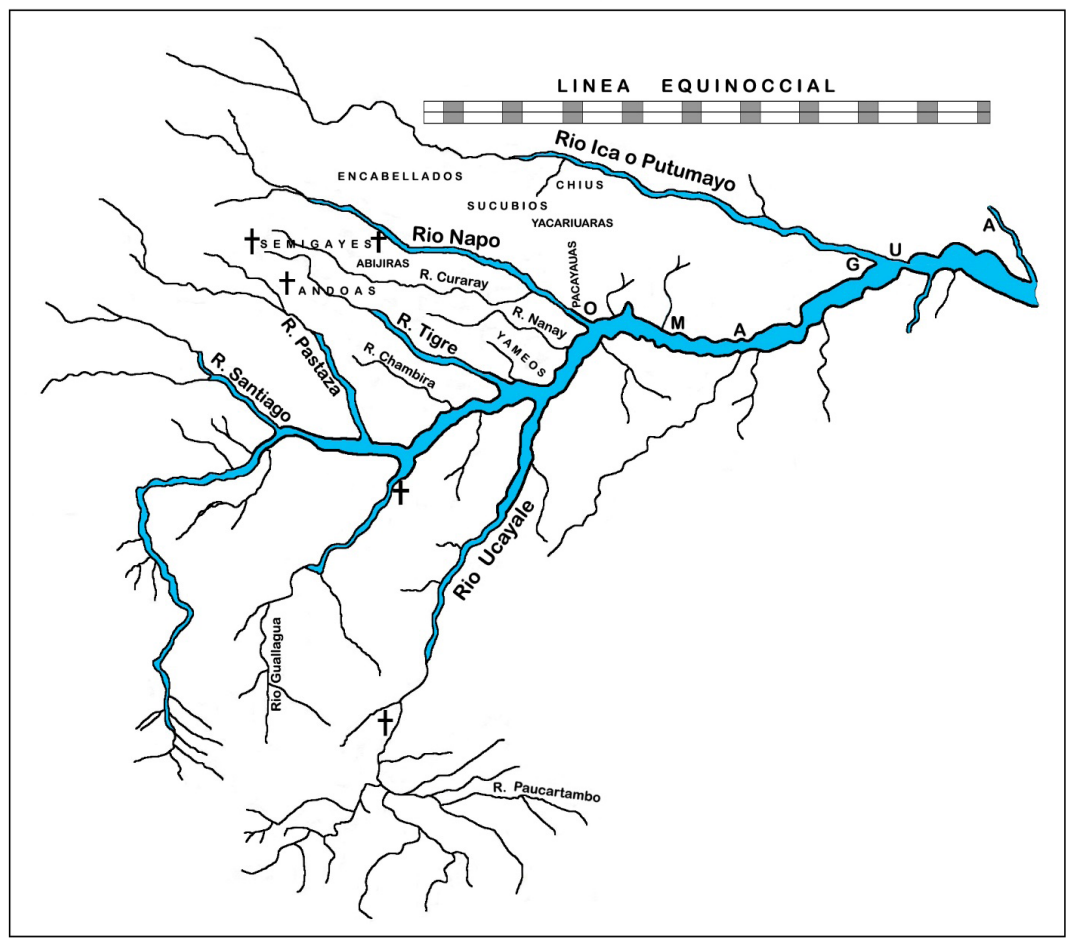

A partir de la boca del Napo la etnia Omagua está asociada a la orilla izquierda del Amazonas, hasta la confluencia del río Yupui. En la orilla derecha del Napo, dos grupos étnicos se ubican entre los ríos Curaray y Napo: Semigayes hacia las cabeceras del Curaray y Abijiras hacia la boca del Curaray.

También, es interesante mencionar el mapa de Perú elaborado por Philippe Buache en 1739 para su inclusión en "Historia de los Reyes Incas de Perú" de Garcilazo de la Vega publicado en Francia en 1744. En este mapa los ríos Aguarico, Coca y Curaray están definidos en relación al curso del Napo, y los grupos étnicos mencionados asociados a estos ríos son: Sucumbios, Encabellados, Oas, Semigayes y Abijiras.

Por su parte, Newson (1996:12) en el contexto de la densidad demográfica en 1492 en el oriente ecuatoriano, presenta un mapa que muestra cinco etnias ocupando las regiones interfluviales desde el Putumayo al Río Curaray: Cofan y Encabellado al Norte del Napo y Semigae, Abijira al Sur del Napo. Los Omagua-Yete están ubicados en las orillas del Coca y alto Napo, y los Omagua amazónicos en las orillas del Napo cerca de su confluencia con el Amazonas.

Finalmente en 1858, Villavicencio en el mapa anexo a su "Geografía de Ecuador”, incluye la presencia de los grupos étnicos Anguteras, Cuiyacos, Cuiyayos, Maisames, Mazanes, Oritos y Yasunies (Markham 1865). Como 
se puede observar, desde la presencia de los jesuitas hasta la descripción de Markham (1865), los principales grupos étnicos ya estuvieron subdivididos en varias ramas y probablemente éstas se fueron expandiendo en la ocupación de la Amazonia norte.

\section{Las evidencias arqueológicas}

Por el momento son muy pocos los sitios arqueológicos con fechas radiocarbónicas que podrían asociarse al período entre 1400 y 1700 d.C. Estos sitios están relacionados con los dos últimos períodos de la tradición de cerámica corrugada-falsocorrugada: $\mathrm{C}^{14}$ cal 900 a 1410 d.C. y $\mathrm{C}^{14}$ cal 1420 a 1600 d.C. en la periodificación descrita por Ochoa (2007) para la región interfluvial Napo-Aguarico. En este sentido consideramos los siguientes sitios: En la región interfluvial Napo-Aguarico: Conambo 1, Jivino Rojo 2, Plataforma Pata 3 (Ochoa, 2007), Pata 1B (Echeverría 2004) y Luz de América (Arellano 2009). En el Alto Napo los sitios: Timbela y Chilumbo (Ugalde 2014), y en las orillas del bajo Napo el sitio Rocafuerte (Evans y Meggers 1968). Al Norte del Aguarico incluímos los sitios asociados a la cuenca del río Putumayo: Santa Teresa del complejo Mocoa (Cifuentes 2006) y Loreto Yacu sitio 14, asociado a la tradición de cerámica polícroma (Bolian 1972). Las fechas de $\mathrm{C}^{14}$ de estos sitios también sugieren una relación entre la región interfluvial del PutumayoCaqueta con las regiones interfluviales de Ecuador.

Los sitios Timbela, Jivino Rojo 2, Conambo 1 y Pata 1B están asociados cronológicamente a las últimas etapas del tercer período de Ochoa (2007). En el cuarto período se ubican los sitios Chullumbo B, Puerto Rocafuerte, Luz de América y Plataforma Pata 3 (Tabla).

Base de datos de fechas radiocarbónicas calibradas d. C. Norte de la amazonía ecuatoriana

\begin{tabular}{l|c|l}
\multicolumn{1}{c|}{ Area-Región/Sitio } & $\begin{array}{c}\text { Rango } \mathbf{C}^{\mathbf{1 4}} \text { cal. d. } \\
\text { C. }\end{array}$ & \multicolumn{1}{c}{ Referencias } \\
\hline Piedemonte-Alto Napo & \multicolumn{3}{|c}{} \\
\hline \multicolumn{3}{|c}{} \\
\hline Timbela & $1285-1410$ & Ugalde (2014) \\
\hline Chullumbo (B) & $1310-1435$ & Ugalde (2014) \\
\hline
\end{tabular}

\begin{tabular}{l|l|l}
\hline Orilla Derecha Río Napo & & \\
\hline
\end{tabular}

\begin{tabular}{l|l|l}
\hline Puerto Rocafuerte & $1328-1552 *$ & Evans y Meggers (1968) \\
\hline
\end{tabular}

Región Napo - Aguarico 


\begin{tabular}{l|l|l}
\multicolumn{1}{c|}{ Area-Región/Sitio } & \multicolumn{1}{c}{$\begin{array}{c}\text { Rango } \mathbf{C}^{\mathbf{1 4}} \text { cal. d. } \\
\text { C. }\end{array}$} & \multicolumn{1}{c}{ Referencias } \\
\hline Conambo 1 & $1280-1410$ & Ochoa (2007) \\
\hline Jivino Rojo 2 (B) & $1290-1410$ & Ochoa (2007) \\
\hline Pata 1B & $1306-1408^{*}$ & Echeverría (2004) \\
\hline Luz de América & $1390-1440$ & Arellano (2009) \\
\hline Plataforma Pata 3 & $1420-1650$ & Ochoa (2007)
\end{tabular}

Sur de la amazonía colombiana

\begin{tabular}{|l|l|l|}
\hline Loreto Yacu-Sitio 14(C) & $1416-1596^{*}$ & Bolian (1972) \\
\hline Santa Teresa & $1430-1592^{*}$ & Cifuentes (2006) \\
\hline
\end{tabular}

*Calibradas por el Autor.

Los sitios del área Pata que se encuentran en el curso medio de la orilla izquierda del río Coca, proporcionaron una apreciable información sobre la ocupación prehispánica desde el Formativo hasta los primeros siglos de la colonia. En la secuencia estratigráfica, cerámica de la tradiciones incisa y punctuada representan las primeras ocupaciones desde apróximadamente $\mathrm{C}^{14}$ cal 250 d.C. En las ocupaciones intermedias se encontraron evidencias de las tradiciones polícroma y corrugada. Al interior de las regiones interfluviales sólo se encuentra la tradición corrugada-falsocorrugada. A partir de $\mathrm{C}^{14}$ cal 1410 d.C. la decoración falsocorrugada pasa a dominar los mediombientes ribereños de los tributarios. La tradición corrugada también fue detectada en el valle del río Suno, situado en el piedemonte andino (Porras Garcés 1987), y al parecer formas y decoración sobrevivieron en la cerámios elaborados por las tribus jíbara y zápara asentadas en los alrededores del río Curaray (Porras Garcés 1975).

De acuerdo a Ochoa (2007) no se puede establecer relaciones entre familias lingüísticas y culturas arqueológicas por que no son indicativos de idéntidades étnicas. Sin embargo, posteriormente acepta la asociación realizada por Metraux (1928) entre la difusión de urnas con decoración corrugada y ungulada con grupos Tupí-Guaraní, en especial Tupinambá establecidos en la cuenca media del Amazonas (Ochoa 2007:469). De igual manera se menciona que los Omagua podrían ser los antecesores de la etnia Shipibo-Conibo en el alto Ucayali y que están relacionados con la cerámica corrugada del complejo Cumancaya (Lathrap 1970). Es decir, es más probable que la cerámica de la tradición corrugada este relacionada con los Omagua.

También se menciona que la cerámica Napo de tradición polícroma tiene filiación Omagua o proto-Omagua, pero no exíste una acceptable evidencia de esta relación. El rango cronológico proporcionadas por las fechas radiocarbónicas de la Fase Napo (cal 725 d.C. a cal 1237 d.C.), no sugieren una cercanía a las 
fechas de la evidencia etnohistórica de la presencia Omagua en el Napo. Por el contrario la presencia Omagua está más cercana a las fechas radiocarbónicas del último período de la tradición corrugada-falsocorrugada en la región interfluvial Napo-Aguarico. Además no exísten evidencias etnohistóricas o históricas de elaboración de cerámica con diseños Napo en los grupos étnicos del norte de la Amazonía de Ecuador. La etnia Cofán originaria del piedemonte amazónico, vendría a ser la única que actualmente tiene una tradición en la elaboración de vasijas de cerámica artesanal con diseños geométricos pintados. Sin embargo los diseños están cercanos a los diseños decorativos geométricos del falsocorrugado. Así mismo las formas de las vasijas Cofán son sencillas, mayormente cuencos y ollas, mientras las formas comunes en los últimos períodos de la tradición corrugada-falsocorrugada son ollas carenadas y urnas elipsoidales con bordes evertidos (Ochoa 2007; Arellano 2009) (Figura 4).

Figura 4: Fotografía de fragmentos de cerámica de la tradición corrugada.

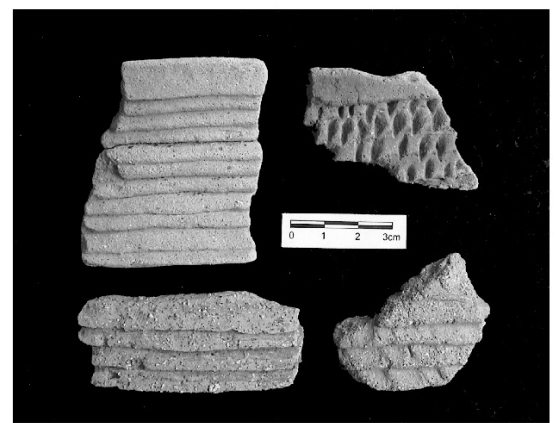

A

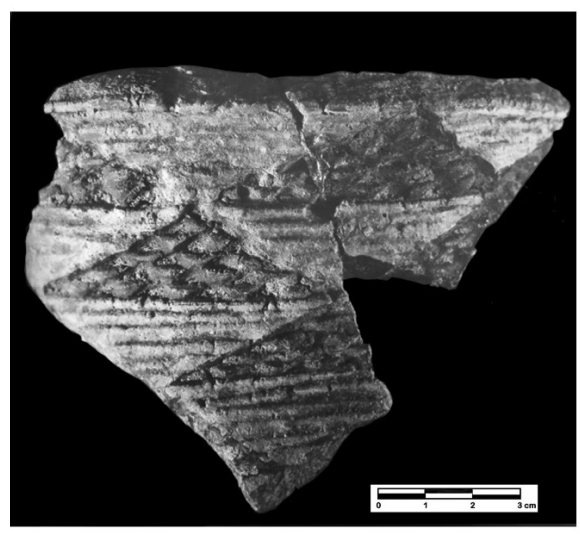

C

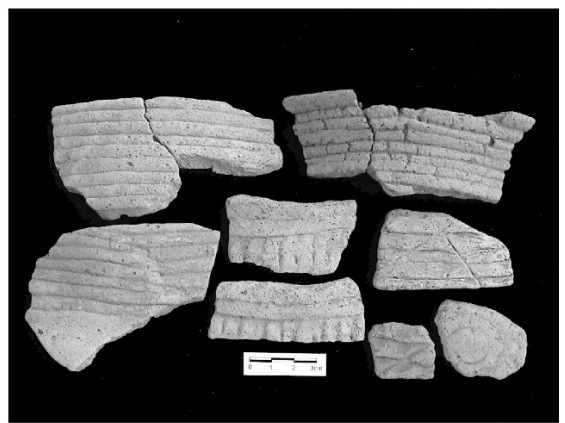

B

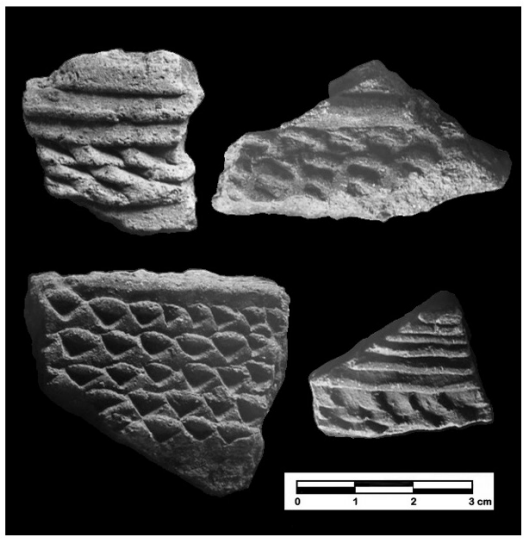

D

A) Sitio Aguarico, orilla derecha del río Aguarico. B) Sitio Shushufindi, interior de la región interfluvial Napo-Aguarico. C) Fragmento con decoración falsocorrugado pintado (modificado de Cuyabeno Ancestral, 2003). D) Aguarico, fragmentos con estilos decorativos del falsocorrugado (modificado de Cuyabeno Ancestral, 2003). 
Lamentablemente no exísten datos arqueológicos de las áreas anexas a las orillas de la confluencia del Napo con el Amazonas, donde etnohistóricamente fué ubicado Aparia menor, tampoco de la región de Aparia mayor. De manera que por el momento no es factible considerar que los Omagua prehispánicos fueron portadores de la tradición polícroma de la fase Napo.

Por otra parte, Ochoa (2007) menciona a Metraux (1928) para indicar que los Omagua podrían haber estado establecidos en las cabeceras del río Jivino que atraviesa parte de la región interfluvial entre el Napo y Aguarico. Esta conclusión fué previamente mencionada por Chaumeil y FraysseChaumeil (1981) en su estudio acerca de las migraciones Omagua desde la región amazónica denominada Aparia Mayor. En este trabajo se indica que los Omagua prehispánicos se desplazaron desde Aparia Mayor a Aparia Menor y posteriormente hacia la región denominada El Barco en las orillas del río Coca. También se menciona que más tarde en los siglos XVII y XVIII existieron migraciones Omagua hacia y desde El Barco. Considerando las evidencias arqueológicas, las orillas del Coca y región anexa estuvieron ampliamente dominadas por el estilo falsocorrugado de la tradición de cerámica corrugada y es factible considerar que los Omagua fueron en parte los difusores de la decoración falsocorrugada. Es importante indicar que el nombre de Omaguas se encuentra registrado desde 1550 (Chaumeil y Fraysse-Chaumeil 1981), y que los Jesuitas todavía los encontraron ocupando las orillas del bajo Napo en su confluencia con el Amazonas.

Coíncidimos con Ochoa (2007) que las culturas de cerámica de la tradición corrugada de la región interfluvial Napo-Aguarico en sus últimas etapas, establecieron relaciones inter-étnicas y de esta forma adoptaron nuevas técnicas de acabado y estilos decorativos, adicionando pintura al falsocorrugado (Arellano 2014). Sin embargo, el estilo de falsocorrugado pintado se encuentra solo en los sitios concentrados en el área de Lago Agrio, orilla izquierda del Aguarico y por consiguiente están asociados a la región interfluvial AguaricoPutumayo.

Las evidencias arqueológicas de la regiones interfluviales Napo-Aguarico y Aguarico Putumayo, sugieren la existencia de una diversidad de tribus desde mediados del período de Integración. Muchas de estas evidencias muestran una continuidad en la ocupación de los territorios tribales, especialmente en el piedemonte donde las tradiciones punctuada y corrugada comparten áreas específicas desde el Formativo. La decoración falsocorrugada fue introducida tardíamente en el período de Integración, y através de la variabilidad de sus estilos decorativos y ocasional pintura se infiere influencias de grupos étnicos asociados con la tradición bicolor del piedemonte andino.

Estas evidencias también sugieren que el piedemonte fué una área marginal de producción e intercambio de recursos naturales entre las sierras subandinas 
y bajo amazonas. En particular el Alto Napo y Alto Aguarico que estuvieron dominadas por la etnias subandinas de los Quijos y Coronado.

\section{Consideraciones finales}

La relación entre las evidencias arqueológicas situadas cronológicamente en el período de $\mathrm{C}^{14}$ cal 1420 d.C. al $\mathrm{C}^{14}$ cal 1650 d.C., y las fuentes documentales y gráficas de los siglos XVI a XVII asociadas con el ingreso español al piedemonte y baja Amazonía del norte de Ecuador, permite observar que existió un desconocimiento de la geografía y de los grupos étnicos que habitaron el interior de las regiones interfluviales. En este sentido, solo dos grandes etnias llamaron la atención desde el siglo XVI, los Omagua y los Encabellados. Esta última etnia estuvo conformada por varias tribus y subtribus asentadas en el Cuyabeno, por los Cofanes de las riberas del Aguarico e Yguacates de los afluentes del Napo (San Román 1994:22).

A partir de la entrada de Pizarro y Orellana a la vertiente oriental de los Andes y al Amazonas en 1541-42, se puede considerar el inicio de un período de transición socio-económico de las culturas étnicas subandinas y amazónicas hasta la entrada de los primeros misioneros en 1636. Luego de la fundación de la ciudad de Baeza en 1559, posteriormente refundada en 1561 (Porras 1974), las etnias subandinas sufrieron una violenta transformación social. Sin embargo, las sociedades amazónicas de las regiones interfluviales continuaron con su tradicionales modos de vida, esta característica se infiere por el patrón de ocupación que muestran la disposición geográfica de las evidencias arqueológicas.

Los promedios de fechas radiocarbónicas calibradas representados en la Tabla 1, indican que el Alto Napo estuvo ocupado por la tradición corrugada desde alrededor de $\mathrm{C}^{14}$ cal 1360 d.C. Mientras en la región interfluvial NapoAguarico se encuentran evidencias de cerámica corrugada desde el período Formativo. Más tarde el corrugado simple usualmente limitado al borde de las vasijas, evoluciona a la decoración falsocorrugada con diversos estilos decorativos y se expande hacia el cuerpo de las vasijas. En esta región, la distribución geográfica del falsocorrugado muestra que en el $\mathrm{C}^{14}$ cal 1410 d.C. tuvo completo dominio del territorio entre el curso del río Coca y la población de Nueva Vida en las cabeceras del río Pañayacu (Figura 5). En el bajo Napo que corresponde a Ecuador, una aislada evidencia de la tradición corrugada ubicada en el área de Roca Fuerte, tiene una fecha promedio de $\mathrm{C}^{14}$ cal 1440 d.C. 
Figura 5:Mapa de las regiones interfluviales del Norte amazónico de Ecuador con ubicación de evidencias arqueológicas asociadas a los grupos étnicos OmaguaYete y Encabellados entre el 1400 y 1600 d.C. (modificado de Arellano, 2014)

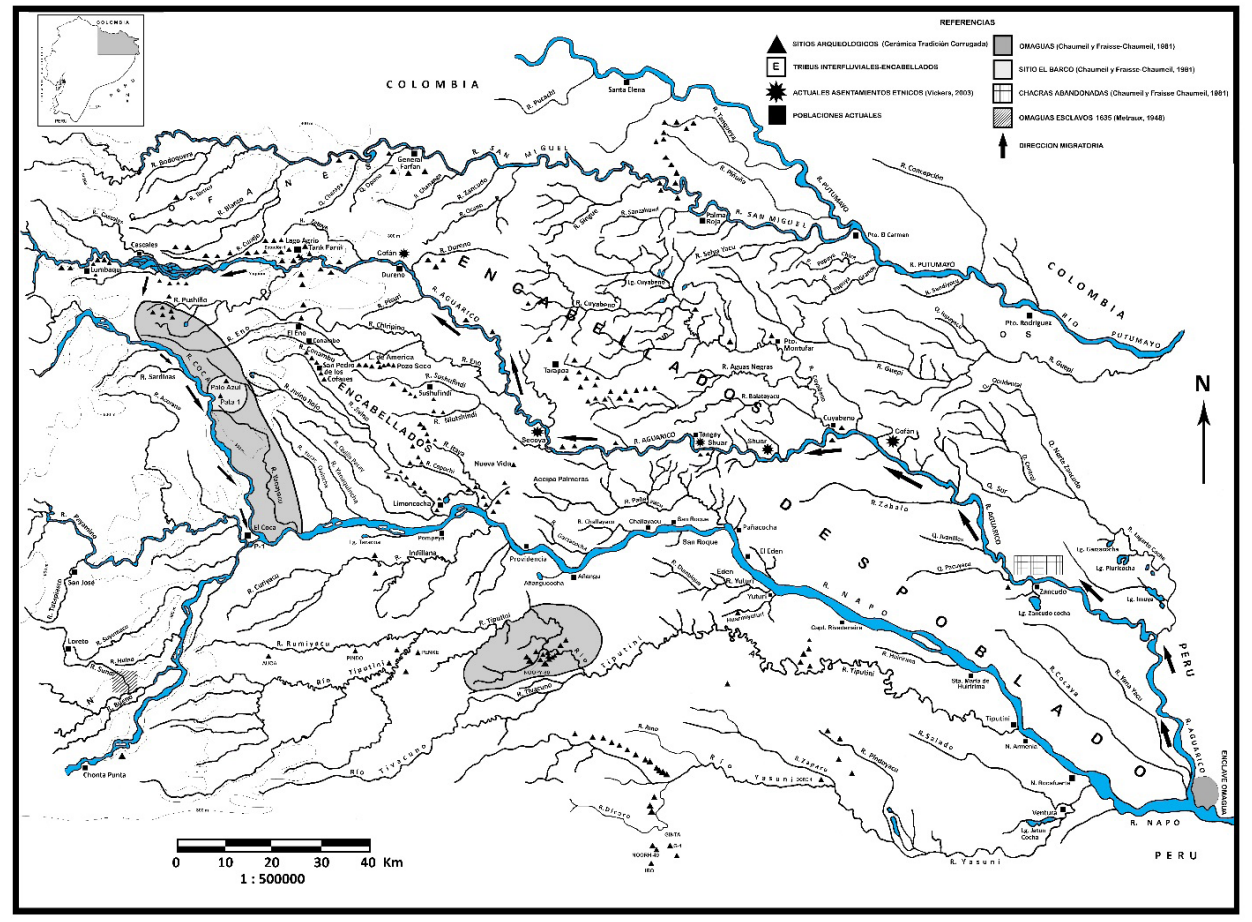

En el curso del Aguarico y hacia el norte, la tradición de cerámica corrugada también tuvo un amplio dominio, aunque por la falta de fechas radiocarbónicas no está establecido si fué el resultado de la expansión TupiGuaraní (Omagua). Los sitios arqueológicos ubicados en el área circundante a Lago Agrio, proporcionaron evidencias de un estilo falsocorrugado pintado que puede implicar una relación con el piedemonte subandino del alto Aguarico y Putumayo.

El panorama en la Amazonía Colombiana es diferente puesto que las tradiciones polícroma y corrugada se encuentran hasta el $\mathrm{C}^{14}$ cal 1508 d.C. y los contactos con el subandino se efectuaron através del Alto Putumayo. En la región de Mocoa la tradición corrugada cronológicamente se ubica desde "el siglo XI hasta el período colonial” y está representada por "vasijas globulares, cuencos y platos" con decoración corrugada en los bordes (Patiño 1994-95, Cifuentes 2006).

Los mapas en particular muestran de manera general la ubicación de las tribus asentadas en las orillas de los ríos asociados con el curso del río Amazonas. La descripción más detallada sobre la presencia de tribus entre la boca del río Napo y la boca del río Negro, fué proporcionada consecutivamente desde 1691 
por Samuel Fritz. Aunque Fritz habría recorrido con frecuencia el Napo desde sus cabeceras, no menciona ningún grupo desde la boca del río Coca hasta la confluencia del Napo con el Amazonas. Esta particularidad coincide con la descripción de Carvajal (1955) sobre la inexistencia de aldeas en las orillas del Napo hasta el descubrimiento de Aparia Menor. Es importante mencionar que las evidencias arqueológicas asociadas con la cerámica Napo se ubican cronológicamente alrededor de 300 años anteriores al recorrido de Orellana y Carvajal.

De manera similar, en los mapas se observa que en el curso del Napo no se incluyen nombres de tribus entre el área del enclave de los Omagua-Yete del Coca y las aldeas Aparia Menor y Aparia Mayor, aspecto que puede interpretarse como espacios geográficos de tierras despobladas. Esta característica también es confirmada por Chaumeil y Fraysee-Chaumeil (1988).

Si bien las orillas del Napo se encontraban despobladas, el patrón de ubicación de los sitios arqueológicos de la tradición corrugada-falsocorrugada sugiere la presencia de varias tribus de un solo grupo étnico y/o lengua ocupando territorios en los cursos de los ríos tributarios de las regiones interfluviales.

Por otra parte, los datos medioambientales sugieren que los Omagua-Yete asentados en las orillas del Coca, cerca del piedemonte marginal andino, por la recurrencia de eventos catastróficos asociados con el subandino, se refugiaron en el interior de la región interfluvial Napo-Aguarico. Es probable que violentas inundaciones pudieron haber ocurrido poco antes de la entrada de Pizarro al curso del río Coca. También y sin lugar a dudas las tribus de la tradición corrugada conocían las condiciones medioambientales de las regiones interfluviales, donde existía menor degradación de recursos naturales. La capacidad de adaptación de estas tribus a diferentes medioambientes, está también sugerida por la disposición de sitios arqueológicos alrededor de pantanales en la cuenca del río Cuyabeno (Arellano 2011).

Através de Chaumeil y Fraysee-Chaumeil (1988), se puede sugerir que la secuencia cultural-histórica de la ocupación Omagua entre 1400 a 1600 en el Norte de la Amazonía Ecuatoriana podría ser la siguiente: Primero, habitaron la orilla izquierda y las islas situadas en el curso medio del Amazonas (Aparia Mayor). Luego pasaron a habitar las orillas del Amazonas en la boca del Napo (Aparia Menor). Posteriormente las orillas del curso medio del Coca (enclave compartido con los Yete). Finalmente estuvieron establecidos en el curso medio del río Tiputini. Esta última ocupación entre los siglos XVII y XVIII, probablemente fue inducida por los Jesuitas con la creación de una misión. Es importante citar a Metraux (1948:690) para mencionar la presencia de una colonia Omagua-Yete en la boca del río Aguarico. También que, "en 1635 fueron llevados como esclavos al río Suno, se rebelaron, y algunos migraron a las cabeceras del río Tiputini”. 
En principio las evidencias arqueológicas y luego las etnohistóricas, sugieren que las principales migraciones Omagua se efectuaron por medio del curso del Aguarico hasta las cabeceras del río Eno y luego se desplazaron hacia las orillas del Coca. Si se toma encuenta las escasas evidencias arqueológicas del Alto Putumayo, también se puede considerar al curso del Putumayo como otra ruta de expansión hacia el piedemonte. Es interesante hacer notar que el mapa de Acuña de 1680, hace referencia a un grupo Omagua entre el alto Putumayo y alto Caqueta, y es probable que las evidencias arqueológicas de la tradición polícroma asociada a la corrugada ubicadas en el alto Putumayo, tengan alguna relación con este grupo.

Es indudable que los Omagua fueron desarticulados socialmente en varios grupos tribales por la constante presión de esclavistas portugueses y sus aliados tribales. Esta fragmentación cultural influyó negativamente en su modo de producción económica, induciendo una permanente movilidad migratoria hasta el punto de desintegrar y desaparecer su territorio étnico y fusionarse con otros grupos étnicos. Los recientes estudios lingüísticos del origen de la lengua Kokama del Alto Ucayali, determinaron que proviene de la lengua Kokama/ Omagua de raíces Tupí-Guaraní y que al final del siglo XVII perdió sus rasgos genéticos originales (Cabral 1995:305). Es decir, se puede inferir que los ríos Huallaga y Ucayali también fueron rutas de contacto y que con através de estas se expandió la cultura material con rasgos Tupí-Guaraní. Marcoy (1869) menciona un pueblo Omagua como parte de"cinco pueblos de la jurisdicción civil y eclesiástica de Nauta", ubicada en el Marañon cerca de la confluencia del Ucayali. Según Metraux (1948) citando a Tessmann (1930), indica que más de un centenar de Omaguas todavía habitaban en las aldeas Sán Salvador y Sán Joaquín, ubicadas en el Marañon-Amazonas.

El siguiente grupo étnico mencionado en mapas y documentos que incluyen el Norte amazónico de Ecuador, son los Encabellados que tuvieron sus aldeas en el interior de las regiones interfluviales Napo-Aguarico y Aguarico-Putumayo, y sólo salieron a las orillas de los ríos navegables al influjo de la creación de misiones-reducciones (Casanova 1988). Al parecer antes de la primera entrada del jesuita Rafael Ferrer en 1600, las diferentes tribus integradas bajo el nombre de Encabellados no tuvieron incentivos socio-culturales y económicos para propender a una expansión fuera de las regiones interfluviales.

De acuerdo con Steward (1950), los Encabellados ocupan la orilla izquierda del Napo junto a los Sioni y Pioje, que junto a los Secoyas y Angoteras también son considerados Encabellados (San Román, 1994). En las cercanías de la confluencia del Aguarico con el Napo se encuentran los Coto. Todos pertenecientes a la família lingüística Tucano. En la orilla derecha el único grupo étnico representado por Steward (1950) es el Awishira, según el mapa de Fritz (1707) es Abijira, y Markham (1865:144) indica que también son conocidos como Avigira, Auxira y Abira, y que tienen la misma lengua y costumbres 
que los Iquitos. El registro de Fabre (1994:94) indica que los Awishira tienen una lengua aislada autodenominada tekiráka, y Tessmann (1930) que 30 a 40 Awishiri se encontraban en Shiripuno región del río Tiputini y 25 en el lago Vacacocha cerca de Puerto Elvira en el Napo.

Por otra parte, la ubicación geográfica de los Encabellados en los mapas del siglo XVI cubren la mayor parte de la región interfluvial entre el Aguarico y Putumayo. Si se consideran las evidencias arqueológicas de ambas regiones bajo el dominio de los Encabellados, se observa una directa asociación a la cerámica de la tradición corrugada. De manera que es evidente que esta etnia estuvo influenciada por la expansión de la decoración falsocorrugada.

Los datos que proporcionan jesuitas y franciscanos para las regiones interfluviales del Napo-Aguarico y Aguarico-Putumayo, se refieren a cinco grupos étnicos y no especifican tribus, probablemente porque consideraron que las región amazónica marginal fue de manera definitiva posesión de la corona española. También se puede inferir que las tribus preferían los contactos con los misioneros en las orillas de los cursos de los ríos Napo, Coca, Aguarico y ocasionalmente Sán Miguel, y no permitían el ingreso al interior de sus territorios. Asímismo, pocos documentos se refieren a misioneros que hayan ingresado a los bosques utilizando cursos de pequeños ríos tributarios.

Es importante destacar que, los Jesuitas fueron los que reconocieron la importancia del registro de las tribus a lo largo del curso del Amazonas, para consolidar las posesiones de la orden y luego para establecer la posesión de las tierras por la corona española. En este particular caso, el informe de Fritz de 1692 y su mapa de 1707, proporcionan evidencias objetivas de la diversidad de tribus que estuvieron asentadas en el curso del Amazonas, desde la confluencia del Napo hasta su desembocadura en el Atlántico.

En consecuencia, en el norte de la Amazonía de la actual República de Ecuador, los primeros contactos españoles fueron efectuados con los OmaguaYete. Las únicas evidencias de grupos al interior de las regiones interfluviales provienen de investigaciones arqueológicas, y es posible que pertenezcan a tribus de la etnia "Encabellado" influenciadas por los Omagua-Yete. La hetereogeneidad decorativa en la cerámica falsocorrugada también sugiere que el grupo étnico Encabellado adquirió tardíamente este estilo decorativo por influencia Omagua. En el siglo XVI el grupo étnico amazónico mejor conocido fue el de los Omagua. A partir de 1600 se incluyó a los Encabellados (Figura 5) y al final del siglo XVII se incluyeron varias tribus al influjo de los expediciones de los jesuitas. En 1701 las siguientes provincias étnicas fueron conocidas: En la orilla izquierda del Napo: Encabellados, Sucumbios, Chius y Yacariuaras. Mientras en la orilla derecha del Napo fueron conocidos los Semigayes y Abijiras.

Finalmente, consideramos que esta primera apróximación arqueológica- 
histórica evolucionará progresivamente con el registro de nuevos datos arqueológicos, etnohistóricos y etnolingüísticos para el período comprendido entre 1400 a 1600 d.C.

\section{Referencias}

Aguilera, María. 2003. Del San Miguel hacia el Norte. En: Cuyabeno Ancestral: 49122. Ediciones Simbioe - GAIA - WALSH Ecuador, Quito.

Arellano, A. Jorge. 2009. Culturas Prehispánicas del Napo y el Aguarico, Amazonía Ecuatoriana. Centro Cultural Pío Aza, Taraxacum Washington D.C., Walsh Environmental Scientists and Engineers Ecuador. Lima.

2011. El manejo prehispánico del paisaje en zonas marginales de la Amazonía: La Amazonía Norte de Ecuador y la zona Norte de las tierras bajas de Bolivia. En: Por donde hay soplo, Estudios amazónicos en los países andinos: 89-136. Eds. J-P. Chaumeil, O. Espinoza de Rivero y M. Cornejo Chaparro. Actas y Memorias 29. IFEA, PUCP, CAAAP, CEREA. Lima.

2014. La densidad de población prehispánica durante el período de Integración (500-1500 d.C.) en las regiones interfluviales del Norte de la Amazonía de Ecuador. INDIANA, Vol. 43 (1): 111-132.

Bolian, Charles E. 1972. An Archaeological Survey of the Trapecio of Amazonas, Colombia. Paper presented at the 1972 al Northeastern Anthropological Meetings, April 21-23, Buffalo, New York.

Cabral, A. S. A. C. 1995. Contact-Induced Language Change in the Western Amazon: The non-genetic origin of the Kokama Language. Ph.D. dissertation, Faculty of Arts and Sciences, University of Pittsburg.

Carvajal, Gaspar de. 1955. Relación del Nuevo Descubrimiento del famozo Río Grande de las Amazonas. Biblioteca Américana, Fondo de Cultura Económica, Mexico.

Casanova V., Jorge. 1998. La misión jesuita colonial entre los Aido Pai (Secoya) y los asentamientos indígenas. Investigaciones Sociales, No. 2: 25-37. Bogota.

Chaumeil, Jean-Pierre y J. Fraysee-Chaumeil. 1981. La canela y el Dorado: Les indigenes du Napo et du Haut-Amazone-Aux XVIe Siecle. Bolletin de l'Institut Français d'Études Andines IFEA, 10 (3-4): 55-86. Lima.

Cifuentes, Arturo. 2006. Arqueología del Piedemonte Amazónico, Putumayo (Colombia). En: Pueblos y Paisajes Antíguos de la Selva Amazónica. Eds. Gaspar Morcote R., Santiago Mora C. y Carlos Franky C. Universidad Nacional de Colombia y Taraxacum Washington D.C.

Colleoni, Paola y José Proaño. 2010. Caminantes de la Selva, Los pueblos en aislamiento en la Amazonía Ecuatoriana 7. CONAIE - IPES - IWGIA. Quito.

Echeverría, José. 2004. Exploration archéologique sur la plataforme Pata 1, communauté de Huataraco, San Sebastián del Coca. En: Actes des Séminaries et ateliers scientifiques du 30e de l'ORSTOM/IRD en Equateur. Octobre 2004: 67-69. Quito. 
Emerson, M. R. y R. H. Johnson. 1961. A Secoya tribe in the Oriente of Ecuador. Man, 61: 201-203.

Evans, Clifford y Betty J. Meggers. 1968. Archaeological Investigation on the Rio Napo, Eastern Ecuador. Contributions to Anthropology, Vol. 6. Smithsonian. Washington D.C.

Fabre, Alain. 1994. Las lenguas indígenas sudamericanas en la actualidad: diccionario etnolingüístico clasificatorio y guía bibliográfica. Tampere.

Ferdon, Edwin N. 1950. Studies in Ecuadorian Geography. Monographs of the School of American Research 15. University of Southern California. California.

Fritz, Samuel. 1654-1724. The Marañon or the Amazon River with the Missions of the Society of Jesus. Disponible en https://www.wdl.org/en/item.1137

Guffroy, Jean. 2006. El Horizonte corrugado: correlaciones estilíticas y culturales. Bulletin de l'Institut Francais d'Etudes Andines 35 (3): 347-359. Lima.

Izaguirre, Bernardino. 1922. Historia de las Misiones Franciscanas y Narración de los Progresos de la Geografía del Oriente del Perú. Talleres Tipográficos de la Penintenciaría, Lima.

Lathrap, Donald W. 1970. The Upper Amazon. Praeger Publishers, New York.

Latorre, Octavio. 1988. Los mapas del Amazonas y el desarrollo de la Cartografía Ecuatoriana en el Siglo XVIII. Miscelánea Antropológica Ecuatoriana, Serie Monográfica. Quito.

Loreiro Dias, Camila. 2012. Jesuit Maps and the Political Discourse: The Amazon River of the Father Samuel Fritz. The Americas, Vol. 69 (1): 95-116.

Marcoy, Paul. (1869), 2001. Viaje a través de América del Sur: del Oceáno Pacífico al Oceáno Atlántico. IFEA, PUCP, BCRP, CAAAP, Lima.

Markham, Clemens R. 1865. A list of the Tribes in the Valley of the Amazon, Including those on the Banks of the Main Stream, and of All Its Tributaries. Transactions of the Ethnological Society of London, Vol. 3: 140-196.

Metraux, Alfred. 1928. La Civilisation Matérialle des Tribus Tupi-Guarani. Librairie Orientalisté Paul Geuthner, París.

1948. Tribes of the Middle and Upper Amazon River. En: Handbook of South American Indians. The Tropical Forest Tribes. Editor Julian H. Steward. Bulletin 143 (3). Smithsonian Institution - Bureau of American Ethnology, Government Printing Office, Washington.

Morcote-Rios, Gaspar. 2008. Antiguos Habitantes en Ríos de Aguas Negras. Ecosistemas y cultivos en el interfluvio Amazonas-Putumayo, Colombia-Brasil. Instituto de Ciencias Naturales, Facultad de Ciencias, Universidad Nacional de Colombia, Bogotá.

Newson, Linda A. 1996. The population of the Amazonian Basin in 1492: A view from the Ecuadorian Headwaters. Transactions of the Institute of British Geographers. New Series 21 (1): 5-26.

Ochoa, Myriam. 2007. Redefiniendo la Fase Pastaza. En: II Congreso Ecuatoriano 
de Antropología y Arqueología; Balance de la Última Década: Aportes, Retos y Nuevas Ideas. Tomo I: 463-495.

Oberem, Udo. 1967-68. Un Grupo Indígena desaparecido del Oriente Ecuatoriano. Revista de Antropología, Vol. 15-16: 149-170.

Patiño Castaño, Diógenes. 1994-1995. El altiplano Nariñense, el valle de Sibundoy y la ceja de montaña Andina en el Putumayo, Investigaciones de Arqueología de Rescate. CESPEDESIA, Vol. 20 (66): 115-179.

Porras Garces, Pedro. 1974. Historia y Arqueología de la Ciudad Española Baeza de los Quijos, Siglo XVI. Editorial PUCE, Quito.

1975. Supervivencia de tradición cerámica común a las culturas del Alto Amazonas y de manera especial a las de la zona oriental del Ecuador en Sudamérica. Universidad de Panamá, Panamá

1985. Arte Rupestre del Alto Napo-Valle de Misagualli, Ecuador. Artes Gráficas Señal, Quito.

Porras, María Elena. 1987. La Gobernación y el Obispado de Mainas. Ediciones AbyaYala y TEHIS, Quito.

Renard-Casevitz, F. M., Th. Saignes y A. C. Taylor. 1988. Al Este de los Andes. Tomo II, Ediciones Abya Yala-Institut Français d'Études Andines (IFEA), Quito.

Reeve, Mary-Elizabeth. 1994. Regional Interaction in the Western Amazon: The Early Colonial Encounter and the Jesuit Years: 1538-1767. Ethnohistory, 41 (1): 106-138.

Rivet, Paul. 1952. Affinités du Kofán. Anthropos, 47 (1-2): 203-234.

San Román, Jesús. 1994. Perfiles Históricos de la Amazonía Peruana. CETA, CAAAP, IIAP. Iquitos.

Sanson, Nicolas. 1680. The course of the River of the Amazons, Based on the Account of Christopher d'Acugna. Disponible en http://hdl.loc.gob/loc.wdl/brrjbn.139

Santos, Fernando. 1992. Etnohistória de la Alta Amazonía, Siglos XV-XVIII. Colección 500 Años, Ediciones Abya-Yala y MLAL, Quito.

Simson, Alfred. 1878. Notes on the Zaparo. The Journal of the Anthropological Institute of Great Britain and Ireland. 7: 502-510.

1883. Notes on the Napo Indians. The Journal of the Anthropological Institute of Great Britain and Ireland. 12: 21-27.

Sinclair, Joseph H. y Theron Wasson. 1923. Explorations in Eastern Ecuador. Geographical Review. 13 (2): 190-210.

Steward, Julian H. (ed.). 1950. Handbook of South American Indians. Physical Anthropology, Linguistics and Cultural Geography of South American Indians. Smithsonian Institution, Bureau of American Ethnology, Bulletin 143 (6). Government Printing Office, Washington.

Steward, Julian H. y Alfred Metraux. 1948. Tribes of the Ecuadorian and Peruvian Montana. En: Handbook of the South American Indians. The Tropical Forest Tribes. Editor Julian H. Steward. Smithsonian Institution, Bureau of American Ethnology, 
Bulletin 143 (3): 535-656. Government Printing Office, Washington.

Tessmann, Günter. 1930. Die Indianer Nordost-Perus. Grundengendle Forshungen für eine Systemastiche Kulturkunde. Friedrichsen de Gruyert \& Co. Hamburg.

Tyler, Charles D. 1894. The River Napo. The Geographic Journal, 3 (6): 476-484.

Ugalde, María Fernanda. 2014. Entre el contrato y el olvido. La arqueología de la ribera del Napo. INPC, Revista del Patimonio Cultural del Ecuador, No. 6: 56-67. Quito.

Vickers, William T. 2003. The Modern Political Transformation of the Secoya. En: Millenial Ecuador, Critical Essays on Cultural Transformation and Social Dynamics. Editor Norman E. Whitten. University of Iowa Press, Iowa.

Wilson, David J. 1999. Indigenous South Americans of the Past and Present, An Ecological Perspective. Westview Press.

Yopán, Rosa V. A. 2010. Grammar of Kokama-Komilla. Ph.D. dissertation, Department of Linguistics, University of Oregon.

\section{Agradecimientos}

Deseo expresar mís agradecimientos al Departamento de Antropología del Museo de Historia Natural de la Smithsonian Institution en la persona del Dr. Rick Torben, Chair del Departamento, por darme la oportunidad de formar parte de esta prestigiosa Institución. Así mismo a: Dr. Dennis Stanford, Dr. Ronald Bishop, Dr. Paul Taylor, Dr. Mary Jo Arnoldi, Dr. Laurie Burgess y Barbara Watanabe de la Smithsonian Institution, por su permanente apoyo a la conclusión del presente y previos trabajos de investigación. De igual manera al Dr. Mark Turber e Ing. Peter Ayarza de Walsh Environmental Scientists and Engineers Ecuador, con quienes tuve la oportunidad de trabajar en Ecuador. Finalmente, mís agradecimientos a los editores y revisores anónimos por sus valiosos comentarios y sugerencias para mejorar el presente artículo. 